\title{
Study on Development Strategy of Guangdong-Hong Kong-Macau Greater Bay Area: a "the Belt and Road" Perspective
}

\author{
Chuan Geng \\ City University of Macau \\ Macau, China 999078
}

\author{
Jin Shen \\ Yancheng Teachers University \\ Jiangsu, China 224000
}

\begin{abstract}
China's "the Belt and Road Initiative" is a national strategy based on a global perspective. It is also the benchmark for China's economic development for a considerable period in the future. The countries and regions along "the Belt and Road" will also see important opportunities for development. At the same time, "GuangdongHong Kong-Macau Greater Bay Area" is the China's key area on "the Belt and Road". In this paper, from the perspective of "the Belt and Road", discuss important status and development characteristics and analyze the development strategy of Guangdong-Hong Kong-Macau Greater Bay Area in the hope of providing useful intellectual support for its future development.
\end{abstract}

Keywords-the Belt and Road; Guangdong-Hong KongMacau Greater Bay Area; development strategy

\section{INTRODUCTION}

On November 13, 2017, the cover of the latest issue of Time magazine reads "China Won" in both Chinese and English $^{1}$. According to the cover story author Ian Bremer, an American political scientist and President of Eurasia Group, a political risk consultancy, this is the first time that two languages have appeared on the cover of time magazine. In the article How China's Economy is Poised to Win the Future, Today China has become the world's most powerful economy of the country, although the United States remains the world's largest economy, but China is using the stateowned enterprises improve influence both at home and abroad, steadily to catch up with the United States, although the privilege of the dollar as the global reserve currency is likely to last for years, but the pillar of American power -the us military alliance, trade leadership and promotion of western political value, is disappearing, now the leaders of Russia, India, Turkey and other countries are looking for the footsteps of China, Bremer said.

\section{A. The Belt and Road Initiative}

1) Concept: "The Belt and Road" (B\&R for short) is the short name of "The Silk Road Economic Belt and the 21stCentury Maritime Silk Road", September and October,

Time magazine (with the exception of the American edition) November 13,2017
2013, Chinese President XI Jinping has put forward the construction of the "The Silk Road Economic Belt" and "21st-Century Maritime Silk Road" of strategic vision". The proposal of "The Belt and Road Initiative" is a major strategy proposed by the Chinese government after the world economy and China's economy have entered the "new normal" and comprehensively deepen opening up to the outside world and achieve mutual benefits and win-win results, this vision will fully rely on China and relevant countries existing bilateral multilateral mechanism, with the aid of regional cooperation platform, jointly created the interests community, fate community and responsibility community of economic integration, political mutual trust, cultural tolerance [1][2]. Based on the comprehensive literature research, we can construct the main connotation framework diagram of "B\&R", so as to understand the core concepts of "B\&R" more intuitively.

2) Opportunity and challenge: The $\mathrm{B} \& \mathrm{R}$ concept put forward means that the strategic shift of China's opening to the outside world policy in the new period, the idea has attracted the attention and a strong resonance of relevant countries, regions in the world. However, we should also take an objective view of the opportunities and challenges faced by B\&R. From the perspective of opportunities: first, the characteristic business opportunities brought by financial innovation. Second, the collaborative economic opportunities brought by regional innovation. Third, the opportunity of economic restructuring and upgrading was brought by industrial innovation. From the challenges: first, any innovation in the $\mathrm{B} \& \mathrm{R}$ has the potential risks actually, especially virtual economy is given priority to with financial innovation contains a multiplier of risk, so we need to keep on the alert, and do a good job in prevention and coping mechanisms. Second, the implementation of the B\&R must adapt to the domestic economic situation, not blind expansion and eager to achieve. Third, when investment in some developing countries, to the country's political system,

\footnotetext{
This section related definition and the connotation reference B\&R official website http://www.yidaiyilu.gov.cn
} 
legal environment and so on carries on the earnest analysis, do a good job in risk assessment and plan reserves before investment, reduce the investment risk [3] [4].

\section{B. Guangdong-Hong Kong-Macau Greater Bay Area}

1) Concept: "Guangdong-Hong Kong-Macau Greater Bay Area" refers to the urban agglomeration formed by Guangzhou, Foshan, Zhaoqing, Shenzhen, Dongguan, Huizhou, Zhuhai, Zhongshan, Jiangmen and Hong Kong and Macau special administrative regions ${ }^{3}$. "GuangdongHong Kong-Macau Greater Bay Area (Greater Bay Area for short in this paper) "is one of China's three national-level regional development strategies in parallel with the BeijingTianjin-Hebei Strategy and the Yangtze River Economic Belt Strategy, aiming to create a world-class bay along the New York Bay, the San Francisco Bay Area and the Tokyo Bay Area.

"Guangdong-Hong Kong-Macau Greater Bay Area" is not a concept that rises on a whim, but has experienced a complicated development path. In 2009, the "Research on the Coordinated Development of Large-scale Cities and Towns in the Pearl River Delta Region" listed the "Bay Area Development Plan" as a part of the coordination plan for the overall layout of space. In 2010, the governments of Guangdong, Hong Kong, and Macau jointly formulated the Key Action Plan for the Construction of the Livable Bay Area around the Pearl River Delta to implement the abovementioned transboundary regional cooperation. In 2015, the China's National Development and Reform Commission, the Ministry of Foreign Affairs, and the Ministry of Commerce jointly issued the "Vision and Action for Promoting the Joint Construction of the Silk Road Economic Belt and the 21st Century Maritime Silk Road" For the first time, "deepening the cooperation with Hong Kong, Macau, and Taiwan to build Guangdong-Hong Kong-Macau Greater Bay Area" marks the official inclusion of the Greater Bay Area into the B\&R initiative. In 2016, the China's national "Thirteenth Five-Year Plan" once again proposed to "promote the construction of a major cooperation platform for Greater Bay Area and across provinces \& regions", stressing that "Work together to create a large-scale Guangdong-Hong KongMacau Greater Bay Area and build a world-class urban agglomeration". In 2017, Premier LI Keqiang of the Chinese State Council emphasized in the government work report that it is necessary to promote the deepening of cooperation between the Mainland and Hong Kong and Macau, study and formulate development plans for the urban agglomerations of the Greater Bay Area, bring into play the unique advantages of Hong Kong and Macau, and enhance their status and functions in the country's economic development and opening up to the world [5] [6].

2) Significance of the Greater Bay Area: Important status of the Greater Bay Area: From the international point of view, from 2011 to 2015, the GDP of the Greater Bay Area has increased year by year, from 6.24 trillion yuan in
2011 to 8.44 trillion yuan, or approximately 1.22 trillion US dollars, ranking 13th in 2015; The economies of Australia have a comparable GDP, exceeding Spain's \$23.8 billion in the 14th ranking, and $\$ 100$ billion less than the 12th ranked Russia. From a domestic perspective: As of 2016, the total area of the Greater Bay Area is 56500 square kilometers, which only accounts for $0.59 \%$ of the total area of the country; the total population of the Greater Bay Area is 67.99 million, accounting for $4.9 \%$ of the total population; The total GDP of the Greater Bay Area is 9.18 trillion yuan (approximately 1.4 trillion US dollars), accounting for $12.3 \%$ of the country's GDP. The overall economic scale of the Greater Bay Area is comparable to that of South Korea in "Fig. 1".It can be seen that its economic strength is strong and its economic status is high in the country. Some scholars have pointed out that the Guangdong-Hong KongMacau Greater Bay Area will leap to the fourth pole of Chinese economy in the China's "Thirteenth Five-Year Plan".

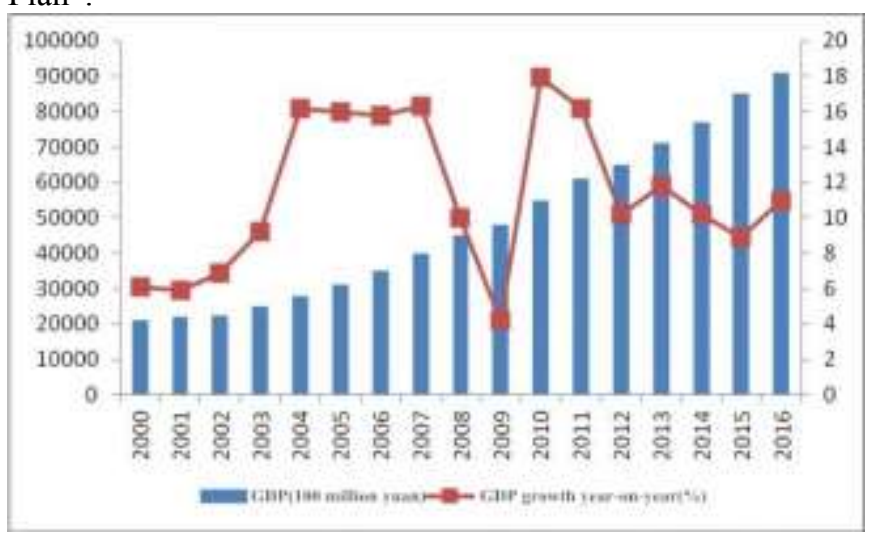

Fig. 1. Economic aggregates and growth charts for the Greater Bay Area.

a. The data comes from Academy of Greater Bay Area Studies.

- The significance of building the Greater Bay Area: From an international perspective, first of all, this strategy will effectively constrain the United States' strategy of "Returning to Asia-Pacific"; secondly, it will help build a new order in Asia and the world; and thirdly, it will continuously enhance China's comprehensive international influence. From the domestic perspective, first, the construction of the Greater Bay Area will promote deeper cooperation between the Mainland and Hong Kong and Macau, bring into play the unique advantages of Hong Kong and Macau, and enhance their position and function in the country's economic development and opening to the outside world. Secondly, it will promote regional economic restructuring and upgrading, and at the same time, it will also boost regional economic hard power and cultural soft power. Third, as the leader of the B\&R initiative, the Greater Bay Area will further play its important role as a core hub.

This section related definition and the connotation reference the website http://ygadwq.gdufs.edu.cn. 


\section{MAIN FEATURES OF GUANGDONG-HONG KONG- MACAU GREATER BAY AREA IN THE BELT AND RoAD}

The main features of the Greater Bay Area in B\&R can be generally understood as the relationship between the "Cultural Collisions": First, the B\&R is a concentrated demonstration of China's reform and opening up, and it is also a manifestation of China's system innovation and reform innovation. Second, the B\&R is a manifestation of China's efforts to build a new global order and a new model of major-country relations. Therefore, the Greater Bay Area is an important "Point" on B\&R. In theory, the two are neither a cut nor an inheritance, but similar to a circle and a point ${ }^{4}$.

\section{A. The Leading Points on $B \& R$}

The Greater Bay Area has the various advantages of the right time and the right place. From right time perspective, the construction of Greater Bay Area has been incorporated into the National vision and Action of Promoting the building of the Silk Road Economic Belt and 21st-Century Maritime Silk Road. From right place perspective, the Greater Bay Area is centered on the Pearl River estuary area, facing the South China Sea on the mainland, is located in the crossroads of international routes, is one of the most developed areas in China and the bridge between China and countries along the Maritime Silk Road. So, the B\&R has provided a superposition of advantages for the construction of Greater Bay Area, and the construction of the Greater Bay Area has also become an effective measure for $B \& R$ Initiative to be launched.

\section{B. The Upgrading of the Pearl River Delta Urban Integration and Development}

Urban agglomeration becomes increasingly important because of the globalization of world economies, the agglomeration of cities is usually better than the economic benefits of urban dispersion [7]. From the perspective of Guangdong's regional development status, the Hong Kong and Macau factors as well as their cooperation with Guangdong have a holistic significance for Guangdong's reform and opening up, the past development experience shows that it is a powerful lever to drive Guangdong's opening up and reform, and also a booster to accelerate economic development. Today, the construction of the Great Bay Area has moved from early regional economic cooperation to a comprehensive national development strategy. It can become an important fulcrum for promoting Guangdong's continuous development and provide favorable opportunities for the transformation of Guangdong's development mode [8][9]. Guangdong, Hong Kong and Macau cooperation is not a new concept, and the proposal of urban agglomeration construction in the Great Bay Area can be seen as an upgrading of the Pearl River Delta urban

\footnotetext{
4 Refer to the summary of the questions and answers by the author and the Prof. Zhang Shujian of Shenzhen University on "Macau and Guangdong-Hong Kong-Macau Greater Bay Area Construction Academic Forum" (December 6, 2017)
}

integration and development including Hong Kong and Macau 5 .

\section{The Industry Integration Leads the Bay Area into the 3.0 Era}

The Bay Area economy is based on the seaport and its physical and geographical conditions. It has developed into a regional economy with an open economy structure, efficient resource allocation capabilities, and developed international networks. Many regions in the world rely on various favorable bay resources to create a number of famous Bay Areas, such as the Tokyo Bay area in Japan, the New York Bay area and the San Francisco Bay Area in the United States, at present, Guangdong-Hong Kong-Macau Greater Bay Area have entered the first phalanx of the global Bay Area economy in "Table. I". The global Bay Area has experienced different stages over time. The earliest Bay Area was the Bay Area 1.0 era, in this era, business and trade shipping centered on ports and docks. Later, it evolved into the Bay Area 2.0 era. The major bay areas in this era include the Tokyo Bay area mainly with advanced manufacturing, the New York Bay Area mainly with financial services, and San Francisco Bay Area mainly with technological innovation. There will be four characteristics in the future Bay Area 3.0 era: highly open, innovative, livable and regional cooperation ${ }^{6}$. The Guangdong-Hong Kong-Macau Greater Bay Area will enter the Bay Area 3.0 era, the major cities in the region can play their respective advantageous industries, go hand in hand, focus on innovation[10].

\footnotetext{
$5 \quad$ Refer to Prof. Chen Guanghan (Professor, Guangdong-Hong Kong-Macau Development Research Institute, Sun Yat-Sen University) 6 Refer to Tan Gang (Vice principal of the Party School of Shenzhen, one of the earliest proponents of the concept of GuangdongHong Kong-Macau Greater Bay Area)
} 
TABLE I. DATA COMPARISON TABLE FOR THE Four MAJOR BAy AREAS IN THE WORLD

\begin{tabular}{|c|l|l|l|l|}
\hline $\begin{array}{c}\text { Index } \\
\text { (2015) }\end{array}$ & $\begin{array}{c}\text { Tokyo Bay } \\
\text { Area }\end{array}$ & $\begin{array}{c}\text { San Francisco } \\
\text { Bay Area }\end{array}$ & $\begin{array}{c}\text { New York Bay } \\
\text { Area }\end{array}$ & $\begin{array}{c}\text { Guangdong-Hong Kong- } \\
\text { Macau Bay Area }\end{array}$ \\
\hline $\begin{array}{c}\text { Population } \\
\text { (10,000) }\end{array}$ & 4347 & 715 & 2340 & 6671 \\
\hline $\begin{array}{c}\text { GDP } \\
\text { trillion dollars) }\end{array}$ & 1.8 & 0.8 & 1.4 & 1.4 \\
\hline $\begin{array}{c}\text { Floor space } \\
\text { (10,000 square kilometers) }\end{array}$ & 3.68 & 1.79 & 2.15 & 5.6 \\
\hline The proportion of the tertiary industry (\%) & 82.3 & 82.8 & 89.4 & 62.2 \\
\hline Top 100 universities in the world & 2 & 2 & 2 & 4 \\
\hline World Top 500 Corporate Headquarters & 60 & 28 & 22 & 16 \\
\hline
\end{tabular}

\section{D. "One Bay Two System" in "One Country Two Systems"}

The development model of Guangdong-Hong KongMacau Greater Bay Area is different from other Bay Area in the world. The first particularity is "one country", judging from the global experience, economic and trade cooperation is mainly the cooperation between the country and the country, for example, the "North American Free Trade Agreement" while the cooperation of Guangdong-Hong Kong-Macau Greater Bay Area is a regional cooperation within a sovereign country. The second particularity is the "two systems", under the premise of China, the cooperative region faces the interconnection of two social systems, two legal systems and two industrial standards. The third particularity is that there are three independent customs regions in the Greater Bay Area, generally is an independent customs region in a sovereign country, but the cooperation of the Greater Bay Area is the cooperation of three independent customs regions within a country. Although it is the regional cooperation within a country, the effect is different from the regional cooperation between mainland provinces, such as working in Guangdong and the mainland provinces, because there is not the problem of customs clearance ${ }^{7}$.

\section{ANALYSIS ON THE DEVELOPMENT STRATEGY OF GuANGDONG-Hong Kong-MaCAU GREATER BAY AREA}

\section{A. Raise "Six Directions" and Focus on "Eight Industries"}

In the future, the construction of the Greater Bay Area should focus on upgrading the six major directions: infrastructure facilities, scientific and technological innovation, B\&R service upgrade, industrial chain of coconstruction and sharing, financial core circle, livable life circle of Bay Area. First, in infrastructure, strengthen infrastructure connectivity, establish an infrastructure system compatible with regional economic and social development, and gradually establish a comprehensive domestic and foreign radiation transportation system. Secondly, scientific and technological innovation, build an innovation community and improve the innovation mechanism, gradually develop it into an important global innovation center for science and technology. Third, in B\&R service upgrade, deepen economic and trade cooperation with countries along the Belt and Road, promote the liberalization

Refer to Prof. Zhang Guangnan (Guangdong-Hong Kong-Macau Development Research Institute, Sun Yat-Sen University) of trade in Guangdong, Hong Kong and Macau, and build an upgraded version of CEPA ${ }^{8}$. Fourth, in industrial chain of co-construction and sharing, continue to foster the benefitsharing industry value chain, accelerate the advancement to the high end of the global value chain, create a modern industrial demonstration region with international competitiveness, and focus on the development of a new generation of information technology, biotechnology, Highend equipment, new materials, etc. Fifth, in financial core circle, build a platform of Guangdong-Hong Kong-Macau financial cooperation, expand the two-way opening financial markets in the mainland and Hong Kong - Macau, create a financial hub that leads the Pearl River Delta, radiates Southeast Asia, and serves the B\&R Initiative, at the same time, actively explore distinctive finance, green finance, technology finance, and uses financial innovation to drive economic diversification. Finally, in the livable life circle of Bay Area, focus on improving the people's livelihood, build internationalized education highland, improve the employment and entrepreneurship service system, to build the Greater Bay Area into a world-class cities cluster that is suitable for business, travel, and life. According to the six major directions, the Greater Bay Area can make economic arrangements in the eight industries: scientific and technological achievements transformation, international education and training, financial services, professional services, business services, leisure tourism, health services, shipping logistics services, and information technology?.

\section{B. Build "China Wisdom Valley" on the Belt and Road}

Guangdong, Hong Kong, and Macau jointly build the "China Wisdom Valley", which will not only increase the practical experience and knowledge reserves for China's future participation in global economic governance and public product supply, but also promote and replicate successful experiences across the country, to help the construction of B\&R. Through constructing "Three Experimental Fields" to build "China Wisdom Valley": The first experimental field is mechanism innovation, which is to take the lead in planning the post-failure and exit mechanism of innovation. Second experimental field is talent innovation, which is to build a new high-end think tank and an

\footnotetext{
8 China's Mainland and Hong Kong - Macau closer economic partnership arrangement for short CEPA

ZTOU Guangdong-Hong Kong-Macau Greater Bay Area Investment Report
} 
international talent cooperation platform. Third experimental field is financial innovation, which is to create "Hong Kong and Shenzhen Exchange" and distinctive finance. Therefore, the construction of the three experimental fields not only conforms to China's "13th Five-Year Plan" and "the Belt and Road Initiative," but also is a new attempt by China to actively participate in the top-level design of international rules and strengthen exchanges with countries along the $\mathrm{B} \& \mathrm{R}^{10}$.

\section{The Challenges of Guangdong-Hong Kong-Macau Greater Bay Area}

The development of the Greater Bay Area will not be easy and it will also face many challenges. First of all, it is the coordination and matching of systems, namely the harmonization of one country, two systems and three tariff zones mentioned above. The second problem is the unbalanced development of the region, there are Hong Kong and Macau, which are highly developed and high GDP, also there are economic prosperity and highly open mainland cities such as Shenzhen, at the same time there are also many cities with average openness such as Huizhou, so there is a real gap in regional economic development. The third is the environmental resources, the development of the Greater Bay Area need good natural environment, but excessive industrialization of the Pearl River delta in the past has caused some problems, for example, the soil, water and air pollution, while the pollution control is difficult, even now a lot of heavy industry still exists, in the long run, this has caused great damage to the natural environment of the Greater Bay Area, GDP may drop steeply if impose excessive demands on it, therefore, it is necessary to carry out remediation step by step. Of course, there are still many difficulties in the development of the Greater Bay Area, but shouldn't shrink because of difficulties. We should see that opportunities outweigh challenges in the course [11].

\section{CONCLUSION}

Although the development of the Greater Bay Area is still in its infancy, there are still some disadvantages compared with the mature world-class Bay Area, an indisputable fact is that the integration of all levels in the Greater Bay Area is accelerating and has already had the basic condition that develops bay area economy[12]. Based on the comprehensive literature analysis, this study made the following conclusions and discussion for the Greater Bay Area:

First of all, all regions in the Greater Bay Area should give full play to their respective advantages and gather those advantages, to form a complementary industrial layout. For example, Hong Kong should align its trade, shipping, finance and professional services industries with manufacturing in the Pearl River Delta. Macau should give full play to the role of platform for economic and trade cooperation between China and Portuguese-speaking countries, and become the main window for mainland enterprises to invest and cooperate with Portuguese-speaking countries.
Secondly, the central government needs to set up a coordination mechanism to plan the long-term development of Guangdong, Hong Kong and Macau. For example, need to set up a development cooperation committee of the Greater Bay Area which will replace some functions of the government. The purpose is to enable the orderly flow of commodities, capital, technology, human resources, and information, so as to achieve the efficient allocation of resources, promote trade and investment facilitation, and reduce transaction costs.

Thirdly, cultivate the benefit-sharing mechanism. The planning of the Greater Bay Area will inevitably involve issues such as benefit sharing, distribution and compensation. Therefore, it is necessary to cultivate the concept of benefit sharing, establish a compensation mechanism and distribution mechanism for regional cooperation, and solve the problem of distribution and coordination.

Fourthly, the Greater Bay Area should draw on the experience of the construction of the world's major bay areas, and use innovation as the core to drive the economic development of the Greater Bay Area, actively learn the manufacturing innovation capability of the Tokyo Bay area, the scientific and technological innovation capabilities of the San Francisco Bay Area, and the financial innovation capabilities of the New York Bay Area. If these three innovation capabilities can be brought together to achieve effective localization, the future Greater Bay Area will become one of the most competitive Bay Area in the world.

Finally, fully integrating the $B \& R$ Initiative, give full play to the geographical advantage and economic advantage of Greater Bay Area, actively carry out investment and cooperation with these countries and regions along the B\&R according to the principle of dislocation development, complementary advantages, mutual benefit.in the large bay area industrial structure adjustment and upgrading, tried to build large bay area into "area" of international operations center. While realizing the industrial restructuring and upgrading of the Greater Bay Area, strive to build it into an international operation center on the Belt And One Road.

\section{REFERENCES}

[1] Su Ge. The Belt and Road Initiative in Global Perspectives[J]. China International Studies, 2016 (2):5-27.

[2] Huang Xiaohui, Zou Kai-min. A Study of the Integration Development of Culture, Commerce and Tourism under the background of "the Belt and Road" Strategy in Guangdong-Hong Kong-Macao Big Bay Area [J]. Journal of south china normal university (Social Sciences) , 2016(4):106-110.

[3] Dai Guoqiang. The "Belt and Road": connotation, meaning and mission of think tank[J]. Journal of China development watch, 2015(4):8-11.

[4] Zou shuai, Song Zihao, Zhang Pengxia. The "Belt and Road": opportunity and challenge coexist [J]. Journal of cooperative economy and technology, 2015(23):5-7.

[5] Zhang Rixin, Gu Zhuotong. The Origin and Next Move of Guangdong-Hong Kong-Macao Greater Bay [J].Reform, 2017(5):6473.

10 Refer to prof. Liang Haiming and prof. Zhao Lei. 
[6] Song Ding. The Background Analysis of Guangdong-Hong KongMacao Greater Bay Area's Strategic Advance [J]. Special Zone Economy, 2017(7):11-13.

[7] Tabuchi T. Urban Agglomeration and Dispersion: A Synthesis of Alonso and Krugman[J]. Journal of Urban Economics, 2005, 44(3):333-351.

[8] Deng Zhixin. Guangdong-Hong Kong-Macao Greater Bay Area: A new engine for the development of the Pearl River Delta [J]. Guangdong Economy, 2017(5):32-35.

[9] Qiu Shan. Dimension Analysis Of Development Direction Choice Of Guangdong-Hong Kong-Macao Greater Bay Area[J]. Social Sciences in Guangdong, 2017(4):15-20.

[10] Chen Chaomeng. Empirical Analysis of Location Pattern of the Port Group in Guangdong-Hong Kong-Macao Greater Bay Area[J].Journal of Shenzhen University (Humanities \& Social Sciences), 2016, 33(4):32-35.

[11] Li Lixun. Some Thoughts on "Guangdong-Hong Kong-Macao Greater Bay Area"'[J]. Tropical Geography, 2017, 37(6):757-761.

[12] Shen Yong, Ma Zhongxin. Constructing the New Pattern of Opening Policy Led by Bay Area Economy: An Empirical Analysis Based on the Degree of Opening in the Guangdong,HK\&Mac Bay Area[J]. The Journal of Shanghai Administration Institute, 2017, 18(1):83-91. 